Article

\title{
An Investigation of Fiber Reinforced Chemically Bonded Phosphate Ceramic Composites at Room Temperature
}

\author{
Zhu Ding ${ }^{1}$, Yu-Yu Li ${ }^{1}$, Can Lu ${ }^{2}$ and Jian Liu ${ }^{1, *}$ \\ 1 Guangdong Provincial Key Laboratory of Durability for Marine Civil Engineering, \\ College of Civil Engineering, Shenzhen University, Shenzhen 518060, China; zding@szu.edu.cn (Z.D.); \\ 13602500403@sina.com (Y.-Y.L.) \\ 2 Infrastructure Construction Department, Shenzhen Polytechnic, Shenzhen 518055, China; lucan@szpt.edu.cn \\ * Correspondence: liujian@szu.edu.cn; Tel.: +86-755-2673-2834
}

Received: 12 April 2018; Accepted: 15 May 2018; Published: 21 May 2018

\begin{abstract}
In this study, chemically bonded phosphate ceramic (CBPC) fiber reinforced composites were made at indoor temperatures. The mechanical properties and microstructure of the CBPC composites were studied. The CBPC matrix of aluminum phosphate binder, metakaolin, and magnesia with different $\mathrm{Si} / \mathrm{P}$ ratios was prepared. The results show that when the $\mathrm{Si} / \mathrm{P}$ ratio was 1.2, and magnesia content in the CBPC was $15 \%$, CBPC reached its maximum flexural strength. The fiber reinforced CBPC composites were prepared by mixing short polyvinyl alcohol (PVA) fibers or unidirectional continuous carbon fiber sheets. Flexural strength and dynamic mechanical properties of the composites were determined, and the microstructures of specimens were analyzed by scanning electron micrography, X-ray diffraction, and micro X-ray computed tomography. The flexural performance of continuous carbon fiber reinforced CBPC composites was better than that of PVA fiber composites. The elastic modulus, loss modulus, and loss factor of the fiber composites were measured through dynamic mechanical analysis. The results showed that fiber reinforced CBPC composites are an inorganic polymer viscoelastic material with excellent damping properties. The reaction of magnesia and phosphate in the matrix of CBPC formed a different mineral, newberyite, which was beneficial to the development of the CBPC.
\end{abstract}

Keywords: chemically bonded phosphate ceramic; fiber reinforced composites; PVA fiber; continuous carbon fiber sheet; acid activation; dynamic mechanical analysis

\section{Introduction}

Chemically Bonded Phosphate Ceramics (CBPCs) refers to a class of materials that are formed by a controlled acid-base reaction, which takes place at lower temperatures compared to sintered ceramics [1]. Although there are ionic, covalent, and van der Waals bonding in CBPC, the dominating are ionic and covalent bonding. CBPCs have high compressive strength, high resistance to high temperature and acidic environments. Their applications can fill the gap between the traditional hydraulic cements and the sintered ceramics [1,2]. CBPCs have many applications in the fields of structures, composites, and biomedical, high temperature environments. They are also utilized in radiation shielding, nuclear waste solidification and encapsulation [3]. Furthermore, the preparation of CBPC is castable, inexpensive, and environmentally friendly. One of the most studied CBPC materials is magnesium phosphate cement (MPC), which is formed by the reaction of magnesium and solution of alkali dihydrogen phosphate [4-11]. The microstructure of MPC based CBPC matrix consists of crystal (newberyite, struvite, and periclase) and amorphous phases [7-9]. These crystals behave like the fine aggregate in cement, which enhances the CBPC's mechanical property and volume 
stability. Although CBPCs have good compressive properties but the tensile strength is relatively poor. Reinforcements, fibers or particles had been used to improve tensile properties, which greatly widened the applications of CBPC [12-14].

The other common type of CBPC is prepared from phosphoric acid and wollastonite [3]. Colorado et al. had carried out intensive research on this type of CBPC composite. Higher performance structure CBPC composites were manufactured with the reinforcements, for instance, nano-fibers, graphite nanoplatelets (GNPs) [15], glass fiber and carbon fiber [16]. The results from Colorado's studies showed that the different fibers improved the properties of CBPC composites at different ranges. CBPC-GNPs showed an improved bending strength (more than $23 \mathrm{MPa}$ without thermal treatment or aging) and high chemical stability below $600^{\circ} \mathrm{C}$. However, the interfaces between CBPC matrix and crystalline phases looks almost cracked, it should be conducted more research to improve the adhesion [15]. For the CBPC prepared by pultrusion method, the bending strength increased by a factor of 29 and 17 for pultruded carbon fiber and pultruded glass-fiber reinforcement CBPCs [16]. However, the pultrusion technique is complicated and higher cost.

In this study, we aimed to provide a simple method to prepare CBPC composite at room temperature, by using an aluminum phosphate binder rather than phosphoric acid. Aluminum phosphate is a type of inorganic binder usually used in refractory ceramics [17]. It is typical to harden aluminum phosphate by heating to elevated temperatures. After it is hardened, it becomes a solid material with high strength, high temperature stability, and good abrasion resistance [18]. However, aluminum phosphates are brittle materials which limit their applications in many important fields. To improve their ductility, researchers have attempted to develop phosphate-based composites using fibers. For example, a German company (Brunswick) has developed a phosphate based radome material [19]. Researchers in the USA have developed quartz fiber reinforced aluminum phosphate based composite materials, which have good mechanical and dielectric properties and can be solidified below $315^{\circ} \mathrm{C}$ and still maintain good performance at $650{ }^{\circ} \mathrm{C}$ [20]. Russian researchers have explored various types of phosphates for creating phosphate-based composites. Among these phosphates, aluminum phosphate has shown excellent mechanical properties and high-temperature stability [21]. However, the preparation of these phosphate-based fiber composites has required elevated temperatures.

The current study investigates the flexural and dynamic mechanical properties of fiber reinforced CBPC composites produced at indoor temperatures. The CBPC matrix was composed of aluminum phosphate binder, metakaolin, and magnesia. Among them, the aluminum phosphate binder used in this study was synthesized from phosphoric acid and aluminum hydroxide, and magnesia was used as the curing agent. Two types of fiber, short polyvinyl alcohol (PVA) fiber, and continuous carbon fiber were used to make CBPC composites. Because the most building structures are under dynamic loads, both the flexural strength and the dynamic elastic modulus of the CBPC composites were measured. The microstructures of the composites were also examined. The reaction products and microstructure of both the CBPC matrix and the fiber composite were characterized by powder X-ray diffraction (XRD), electron scanning micrography (SEM), and micro X-ray computed tomography (XCT) analysis. The XCT analysis can present the distribution of fibers in CBPC composite, and leading to a better understanding of the combination status of fibers and matrix.

\section{Materials and Methods}

\subsection{Raw Materials}

The materials used in the experiment include: metakaolin (Jiaozuo, Henan Province, China), magnesia (Jimei Refractory Company, Zibo, Shandong Province, China), fine aggregate that was ISO standard sand (ISO 679, Amoy i standard sand Co., Ltd., Xiamen, Fujian Province, China), phosphoric acid ( $\geq 85 \%$, Chengdu Kelong Chemical Reagent Factory, Chengdu, China) and aluminum hydroxide (Chengdu Kelong Chemical Reagent Factory, Chengdu, China). The chemical composition of the materials and the average particle size are given in Table 1 . The technical parameters of PVA fiber 
(Kuraray Trading (Shanghai) Co., Ltd., Shanghai, China) are shown in Table 2. The dimensions and physical properties of continuous carbon fiber sheet (Nanjing Haituo Co., Ltd., Nanjing, China) are listed in Table 3.

Table 1. Chemical composition (wt.\%) and average particle size of the main materials $(\mu \mathrm{m})$.

\begin{tabular}{ccccccccc}
\hline & $\mathbf{M g O}$ & $\mathrm{SiO}_{2}$ & $\mathrm{Al}_{2} \mathbf{O}_{3}$ & $\mathbf{C a O}$ & $\mathrm{Fe}_{2} \mathrm{O}_{3}$ & $\mathrm{TiO}_{2}$ & $\mathbf{P}_{2} \mathbf{O}_{5}$ & Average Particle Size $(\mu \mathrm{m})$ \\
\hline Metakaolin & 0.06 & 55.06 & 44.12 & 0.17 & 0.76 & 0.81 & & 8.13 \\
Magnesia & 83.18 & 6.42 & 1.19 & 6.467 & 1.278 & 1.25 & 1.25 & 46.65 \\
\hline
\end{tabular}

Table 2. Technical parameters of polyvinyl alcohol (PVA) fiber.

\begin{tabular}{cccccc}
\hline Diameter $(\mu \mathrm{m})$ & Elongation (\%) & Length $(\mathbf{m m})$ & Young's Modulus (GPa) & Tensile Strength (MPa) & Density $\left(\mathrm{g} \cdot \mathrm{cm}^{-3}\right)$ \\
\hline 40 & 12 & 7 & 41 & 1560 & 1.3 \\
\hline
\end{tabular}

Table 3. Technical parameters of continuous carbon fiber sheet.

\begin{tabular}{cccc}
\hline Thickness $(\mathbf{m m})$ & Heavy $\left(\mathbf{g} / \mathbf{m}^{2}\right)$ & Tensile Strength $\mathbf{( M P a )}$ & Elastic Modulus (GPa) \\
\hline 0.11 & 200 & 3400 & 240 \\
\hline
\end{tabular}

\subsection{Phosphate Solution Preparation}

In this study, aluminum dihydrogen phosphate $\left(\mathrm{Al}\left(\mathrm{H}_{2} \mathrm{PO}_{4}\right)_{3}\right)$ was used as the phosphate binder for making CBPC. It was prepared according to the following reaction equation:

$$
\mathrm{Al}(\mathrm{OH})_{3}+3 \mathrm{H}_{3} \mathrm{PO}_{4}=\mathrm{Al}\left(\mathrm{H}_{2} \mathrm{PO}_{4}\right)_{3}+3 \mathrm{H}_{2} \mathrm{O}
$$

$\mathrm{Al}(\mathrm{OH})_{3}$ was evenly mixed with deionized water, then, the mixture was put into a magnetic stirrer and stirred in a water bath at $180 \mathrm{rpm}$. Next, $\mathrm{H}_{3} \mathrm{PO}_{4}$ was added into the mixture solution evenly and slowly when the water temperature reached $90^{\circ} \mathrm{C}$. Heating continued until water temperature reached $98{ }^{\circ} \mathrm{C}$ and was then held at that temperature. The mixture was stirred uniformly until the transparent substrate glue was observed. The stirring continued for one hour more for evaporating excess moisture. Finally, the phosphate binder solution was synthesized.

\subsection{Test Specimen Preparation}

The raw materials' proportions used in the test specimens are listed in Table 4 . The pure CBPC paste specimen was prepared by mixing phosphate solution, metakaolin, and magnesia, while the composites test samples with PVA fiber were made by mixing CBPC paste and PVA fiber. The blend mixtures were stirred evenly into an adhesive mixture. The mixtures were injected into a mold with the dimensions of $160 \mathrm{~mm} \times 40 \mathrm{~mm} \times 10 \mathrm{~mm}$, then vibrated by using a cement mortar vibrator (ZP-5, Henan Zhongke Engineering \& Technology Co., Ltd., Zhengzhou, China). After three days, the specimens were released and cured in laboratory conditions for 28 days (air temperature: $25 \pm 2{ }^{\circ} \mathrm{C}$; relative humidity: $60 \pm 5 \%$ ). The flexural strength was then tested by an MTS machine (WE-30B, Changchun Testing Machine Institute Co. Ltd., Changchun, China).

The procedure for the preparation of CBPC composites specimens with carbon fiber sheet is as follows: the CBPC paste was firstly mixed with the phosphate binder, metakaolin, and magnesia using the proportions as listed in Table 5 . Then the composites were molded by using CBPC to paste the carbon fiber sheets layer-by-layer. The size of mold was $160 \mathrm{~mm} \times 40 \mathrm{~mm} \times 10 \mathrm{~mm}$. A layer of freshly mixed CBPC paste was evenly placed on the bottom surface of the mold, and then a layer of carbon fiber sheet was laid on the freshly mixed CBPC paste. After that, a layer of freshly mixed CBPC paste was evenly placed on the carbon fiber sheet. The above procedure was repeated several times according to the number of layers of fiber sheets. After this assembly of the composites, the specimens were cured in laboratory conditions then the flexural strength was tested. 
Table 4. Raw materials' mixing proportions of chemically bonded phosphate ceramic (CBPC) composites with PVA fiber.

\begin{tabular}{cccc}
\hline \multirow{2}{*}{ Sample Designation } & \multicolumn{3}{c}{ Mix Proportion } \\
\cline { 2 - 4 } & Si/P Mole Ratio & Magnesia/Phosphate Solution (\%) & PVA Fiber/Binder (\%) \\
\hline P-1 & 1.2 & 0 & 0 \\
P-2 & 1.2 & 0 & 0.8 \\
P-3 & 1.2 & 0 & 1.2 \\
P-4 & 1.2 & 0 & 1.5 \\
P-5 & 1.2 & 12 & 0 \\
P-6 & 1.2 & 12 & 0.8 \\
P-7 & 1.2 & 12 & 1.2 \\
P-8 & 1.2 & 12 & 1.5 \\
P-9 & 1.2 & 15 & 0 \\
P-10 & 1.2 & 15 & 0.8 \\
P-11 & 1.2 & 15 & 1.2 \\
P-12 & 1.2 & 15 & 1.5 \\
\hline
\end{tabular}

Table 5. Raw material mixing proportion of CBPC composites with continuous fiber.

\begin{tabular}{cccc}
\hline \multirow{2}{*}{ Sample Designation } & \multicolumn{3}{c}{ Mix Proportion } \\
\cline { 2 - 4 } & Si/P Mole Ratio & Magnesia/Phosphate Solution (\%) & Number of Continuous Fiber Layers \\
\hline F-1 & 1.2 & 0 & 0 \\
F-2 & 1.2 & 0 & 1 \\
F-3 & 1.2 & 0 & 2 \\
F-4 & 1.2 & 0 & 3 \\
F-5 & 1.2 & 12 & 0 \\
F-6 & 1.2 & 12 & 1 \\
F-7 & 1.2 & 12 & 2 \\
F-8 & 1.2 & 12 & 3 \\
F-9 & 1.2 & 15 & 0 \\
F-10 & 1.2 & 15 & 1 \\
F-11 & 1.2 & 15 & 2 \\
F-12 & 1.2 & 15 & 3 \\
\hline
\end{tabular}

\subsection{Flexural Strength Testing Method}

The flexural strength of CBPC follows the fiber reinforced plastic flexural performance test method (GB/T 1449-2005). Figure 1 shows the test setup of the flexural test with a test specimen in place. The flexural modulus of fiber composites is calculated according to Equation (2).

$$
E_{f}=\frac{\Delta P \cdot L^{3}}{4 b \cdot h^{3} \cdot \Delta S}
$$

where $E_{f}$ is the flexural modulus of elasticity; $\Delta P$ is the load increment of the initial straight line on the load-deflection curve; $\Delta S$ is the deflection increment corresponding to the span midpoint specimen $\Delta P$; $L$ is the span during testing; $b$ is the specimen width; $h$ is the specimen thickness.

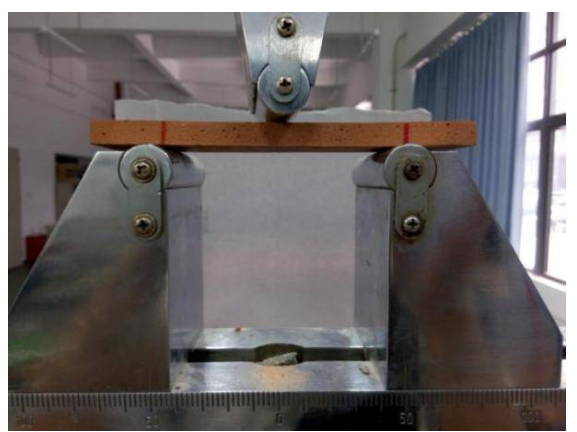

Figure 1. Specimen and three-point bending strength test setup. 


\subsection{Dynamic Elasticity Testing Method}

Dynamic mechanical analysis (DMA) has become a typical method to study the properties of polymer materials in recent years [22]. Phosphate binders are a type of inorganic polymer material so DMA is useful for its study. Physical parameters from DMA represent the dynamic elasticity and include the loss angle $\delta$, storage modulus $\mathrm{E}^{\prime}$, and complex modulus $\mathrm{E}^{\prime \prime}$. In this study, the dynamic viscoelasticity of fiber reinforced CBPC composite was studied by changing the size of the dynamic load and the type of fiber. Viscoelasticity refers to the characteristics of the microstructure of composites in response to external loads, reflecting the multiplicity of its motion units and the hysteresis of response to external loads.

Four groups of samples were prepared and cured according to the procedures mentioned in the Section-Test Specimen Preparation. The material mixtures used are listed in Table 6, and the specimen size was $10 \mathrm{~mm} \times 10 \mathrm{~mm} \times 40 \mathrm{~mm}$. The hardened specimens surface were polished using 600 mesh sandpaper prior to DMA using the dynamic mechanical analyzer (DMA+1000, PerkinElmer, Shanghai, China). The loading range was 10 to $60 \mathrm{~N}$, loading frequency was $2 \mathrm{~Hz}$, and loading amplitude was $10 \mathrm{~N}$.

Table 6. Material mixing proportion of the samples for dynamic mechanical analysis (DMA) by dynamic mechanical analyzer.

\begin{tabular}{cccc}
\hline \multirow{2}{*}{ Sample Designation } & \multicolumn{3}{c}{ Mix Proportion } \\
\cline { 2 - 4 } & Si/P Mole Ratio & Magnesia & Fiber Content \\
\hline D-1 & 1.2 & 0 & - \\
D-2 & 1.2 & $15 \%$ & - \\
D-3 & 1.2 & $15 \%$ & $1.5 \%$ PVA fiber \\
D-4 & 1.2 & $15 \%$ & one layer of carbon fiber sheet \\
\hline
\end{tabular}

\subsection{Microstructure Analysis Method}

To observe the microstructure of CBPC composite, powder X-ray diffraction (XRD) analysis was carried out using a D8 Advance (Bruker, Karlsruhe, Germany). The XRD used $\mathrm{Cu} K \alpha$ radiation $(\lambda=0.154 \mathrm{~nm})$, had a tube voltage of $40 \mathrm{kV}$, and tube amperage of $10 \mathrm{~mA}$. The scanning region was $10^{\circ} \sim 70^{\circ}(2 \theta)$, and step width was $0.05^{\circ}(2 \theta)$. A scanning electron microscope (SEM) (Quanta TM 250 FEG, FEI, Hillsboro, OR, USA) was used for the micromorphological observation of the CBPC specimens. The SEM observations included both pure CBPC paste and carbon fiber samples. The acceleration voltages were 5, 10 and $15 \mathrm{kV}$. Three-dimensional (3D) imaging micro-analysis was conducted for the PAV fiber samples by using Micro XCT-400 (Xradia Inc., Jena, Thuringia, Germany). The sizes of the samples were approximately $0.5 \mathrm{~cm}^{3}$. A large number of two-dimensional (2D) images were extracted, then Avizo software was used for reconstructing 3D images from these 2D images. The specimen with $1 \%$ PVA fiber was tested by this XCT analysis.

\section{Results and Discussion}

\subsection{Flexural Strength of CBPC Composites with PVA Fiber}

The results of the flexural strength testing of CBPC composites with PVA fiber are shown in Figure 2a. It can be seen that when the content of the PVA fiber was the same, the flexural strength of the samples (samples P-1 to P-4) without magnesia was significantly lower than the comparable samples that contained magnesia. Thus, adding magnesia improved the flexural strength of phosphate-based fiber composites for the same curing ages. When the contents of PVA fiber were the same, the flexural strengths of the samples with $15 \%$ magnesia content (samples P-9 through P-12) were higher than that of other samples with the content of $12 \%$ magnesia (samples of P-5 through P-8). The CBPC 
sample mixture with a $\mathrm{Si} / \mathrm{P}$ mole ratio of 1.2 and magnesia content of $15 \%$ developed excellent mechanical properties.

Compared to specimens having no PVA fiber, the flexural strength of CBPC composites with PVA fiber was seen to increase by about two or three times when the content of PVA fiber was $0.8 \%$. With the increase of PVA fiber, the flexural strength of the specimen gradually increased. When the PVA fiber content was $1.5 \%$, the flexural strength increased to $13.86 \mathrm{MPa}$.

In addition, PVA fiber can significantly improve the ductility of the CBPC material. When PVA fiber was not blended into the mixture, a typical brittle fracture occurred immediately when the displacement of the sample reached approximately $0.3 \mathrm{~mm}$. When the PVA fiber content was $0.8 \%$ and $1.2 \%$, the maximum displacements of the specimens were $4 \mathrm{~mm}$ and $6 \mathrm{~mm}$, respectively. At a PVA fiber content of $1.5 \%$, the displacement maximum was $6 \mathrm{~mm}$. However, for this PVA fiber content of $1.5 \%$, the failure mode changed from brittle failure to plastic failure. As this specimen had deformation before failure, a lot of fine cracks formed before final fracture. The test results indicate that phosphate-based short fiber composites have high ductility and provide good resistance to flexural deformation.

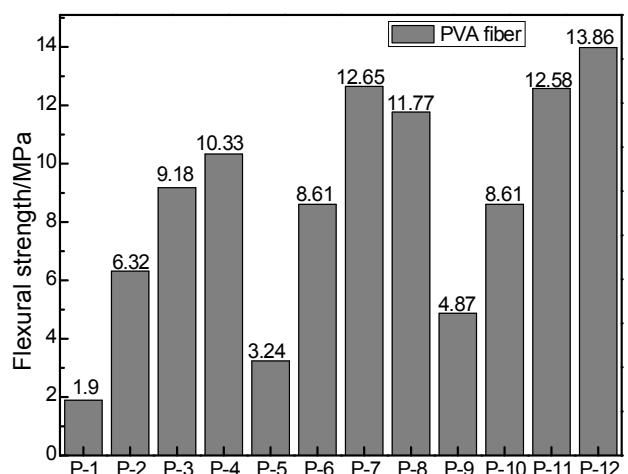

(a)

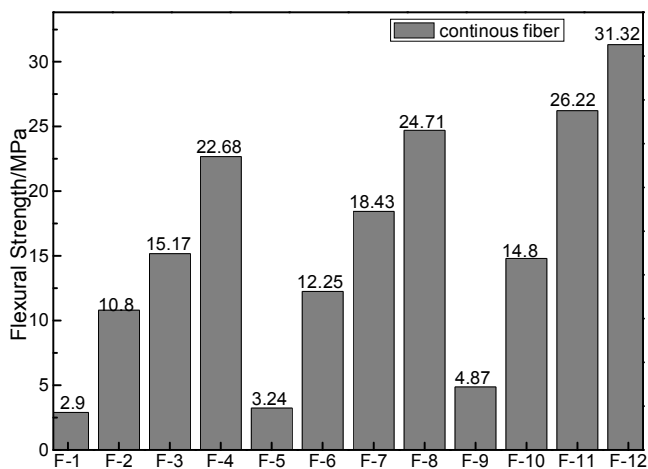

(b)

Figure 2. Flexural strength of CBPC composites with (a) PVA fiber and (b) continuous carbon fiber sheet.

\subsection{Flexural Strength of CBPC Composites with Continuous Carbon Fiber Sheets}

The results of flexural strength testing of CBPC composites with carbon fibers are shown in Figure $2 b$. When the samples had the same number of layers of carbon fiber sheets but had different magnesia contents, the flexural strength values increased with the magnesia content. This increase of flexural strength with magnesia content is seen in the flexural strength of samples F-9 through F-12 being greater than their counterparts in samples F-5 through F-8, which in turn were greater than the comparable samples in F-1 through F-4. When the $\mathrm{Si} / \mathrm{P}$ mole ratio was 1.2 , and the magnesia content was $15 \%$, the CBPC sample had the maximum flexural strength observed in this study.

When magnesia content was at the same level, adding the first layer of carbon fiber sheet gave a flexural strength that was three times that of the sample without the carbon fiber sheet. The single layer composite flexural strength was comparable to the strength of the composite sample with $1.5 \%$ PVA short fiber. The flexural strength increases with increasing the number of fiber sheet layers. When three layers of carbon fiber sheet were used, the flexural strength of the sample reached a maximum of 31.32 MPa. In general, phosphate-based continuous fiber composites have a better flexural resistance than the phosphate-based short fiber composites.

Figure 3 displays the loading-displacement curves of both CBPC composites with short PVA fibers and carbon fiber sheets. Figure 4 shows the failure modes of the control sample and the CBPC composites with short PVA fibers and carbon fiber sheets.

Fiber reinforced CBPC composites had an excellent flexural capacity in the tests. As well, fiber reinforced CBPC composites had better ductility compared to the pure CBPC matrix paste. Based on 
the experimental results, the modulus of elasticity of the sample without the fiber was $2.92 \mathrm{GPa}$. As the layers of the carbon fiber sheet were increased from 1 to 3 , the elastic modulus significantly increased from 5.77 GPa for one layer, 8.31 GPa for two layers, and $10.88 \mathrm{GPa}$ for three layers. As shown in Figure 4, the failure mode of the control specimen was the brittle fracture. Specimens with continuous fiber had a significant number of cracks in from the middle of the specimen that formed because of the constraint action of the continuous carbon fiber. There are small gaps in the carbon fiber sheets as shown in Figure 5 that allow more of the CBPC paste to penetrate. This additional penetration of CBPC likely provides strong bonding between the fiber and matrix. Similar to the short PVA fiber results, phosphate-based continuous fiber composites had high ductility and also gave good resistance to flexural deformation.

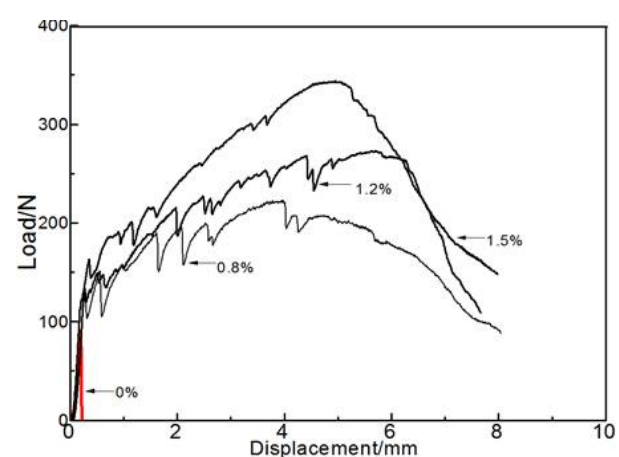

(a)

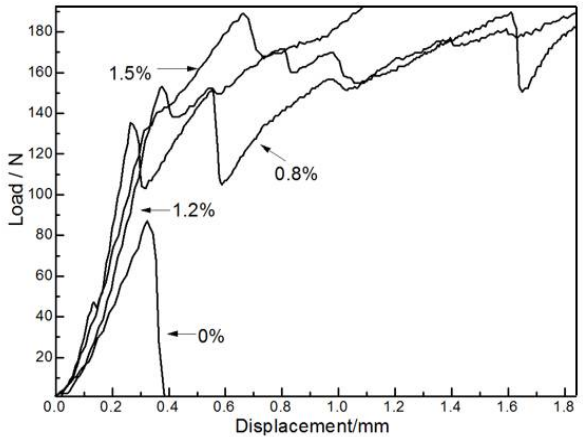

(b)

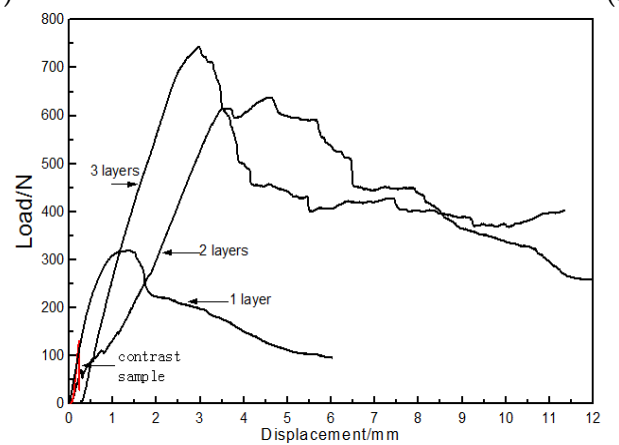

(c)

Figure 3. Loading-displacement curves for (a) CBPC composites with PVA fiber and (b) its partial enlargement; (c) CBPC composites with continuous carbon fiber sheets.

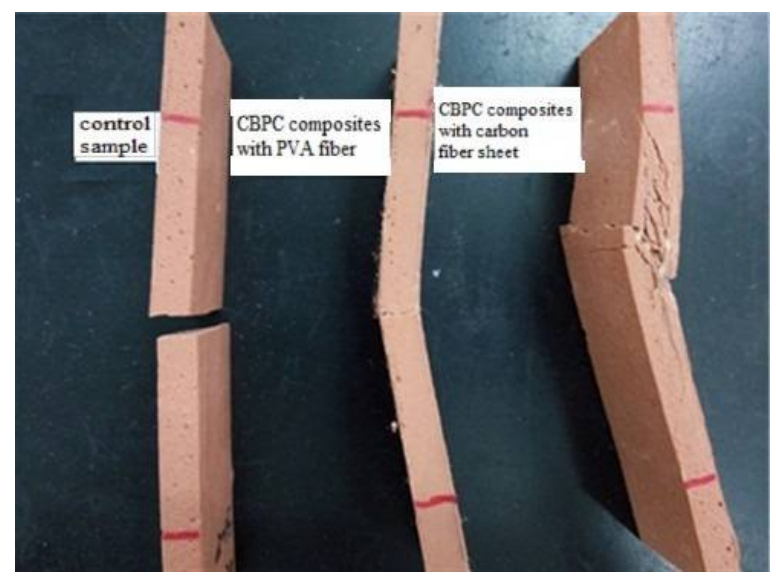

Figure 4. Failure modes of CBPC paste and CBPC composites with PVA fiber and continuous carbon fiber sheet. 


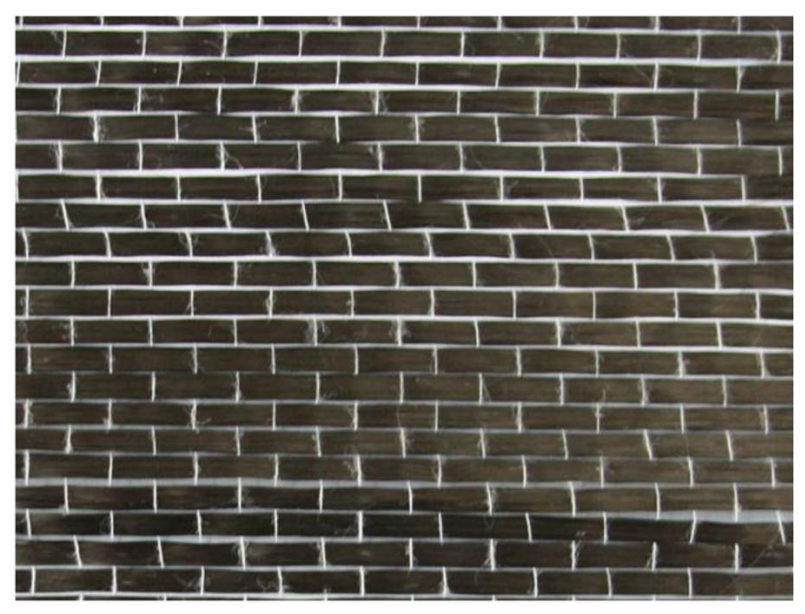

Figure 5. Continuous carbon fiber sheets showing spacing of fibers.

\subsection{Dynamic Elastic Analysis of Fiber Reinforced CBPC Composites}

The mechanical properties of polymer materials are affected by the structure, but also by the size of external forces, time, frequency, and temperature. During the dynamic elastic analysis, a sinusoidal load was applied to the phosphate composites. The material deformation occurred under the external load. The external force for the deformation is split into two parts. One part of the load is stored in the so-called storage modulus $\mathrm{E}^{\prime}$. Another part of the external force changes the molecular chain of the polymer which corresponds to the wasted loss modulus E". The stress and strain of the material under the action of the sinusoidal load were measured by the sensors of the DMA instrument.

The results of dynamic elastic analysis of phosphate-based fiber composites are shown in Figure 6. It can be seen from Figure 6a that the storage modulus of sample D-4 increased at first and then decreased, while other samples showed an increasing trend with loading. Among all samples, the sample D-3 had the maximum storage modulus at all loads.

The magnitude of preloading in the dynamic load scanning is the same throughout. As the material is in the linear elastic range for the entire loading process, the dynamic storage modulus was only slightly changed. For polymer materials experiencing dynamic loading, the storage modulus of the material is the physical quantity related to the elastic deformation. Therefore, the CBPC specimen with short fibers could have increased internal friction of the molecular chain, slowing the slip phenomenon of the molecular chain, thus increasing both the stiffness and the storage modulus. This would explain the increased resistance to deformation. Also, the growth rate of the storage modulus of sample D-2 is faster than sample D- 1 with loading. This difference indicates that the magnesia can effectively enhance the internal friction of the material, leading to the increase of damping, stiffness, and the storage modulus.

According to Figure $6 \mathrm{~b}, \mathrm{c}$, the loss modulus and loss factor increased with dynamic loading. Loss modulus is also known as viscosity modulus, characterizing the ability to dissipate deformation energy and reflect the viscous nature of the material. The greater the loss modulus, the more energy the viscous deformation will lose, the closer the material is to the viscous material. The loss factor also represents the viscoelasticity of the material, proportional to elasticity and inversely proportional to elasticity. For sample D-4, the loss modulus and loss factor may increase so significantly as a result of the large amount of deformation seen in the sample and changes in molecular conformation. In the allowable load range for the test, the larger values of load are of more importance to flexural deformation resistance. So the sample D-4 is more reach to the viscous material. As these higher dynamic loads are reached, the loss modulus has increased, and it is seen specifically that the CBPC fiber composites have an increased resistance to viscous deformation. The loss moduli of the other samples only have low overall growth, and the growth rate is small as well relative to the CBPC 
fiber composites. So the CBPC fiber composites are closer to the viscous material compare to the CBPC paste.

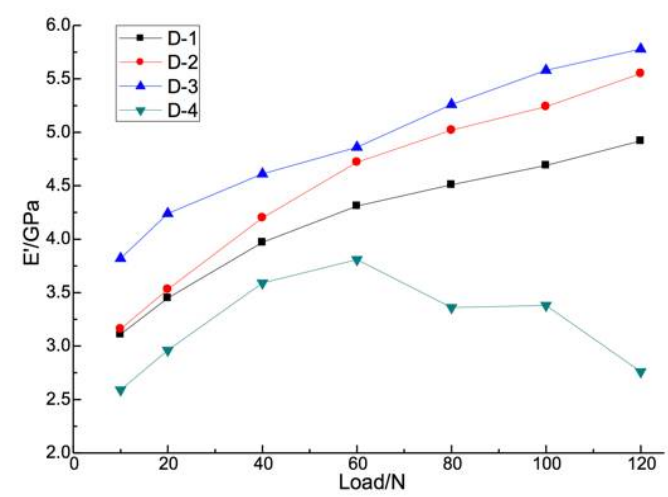

(a)

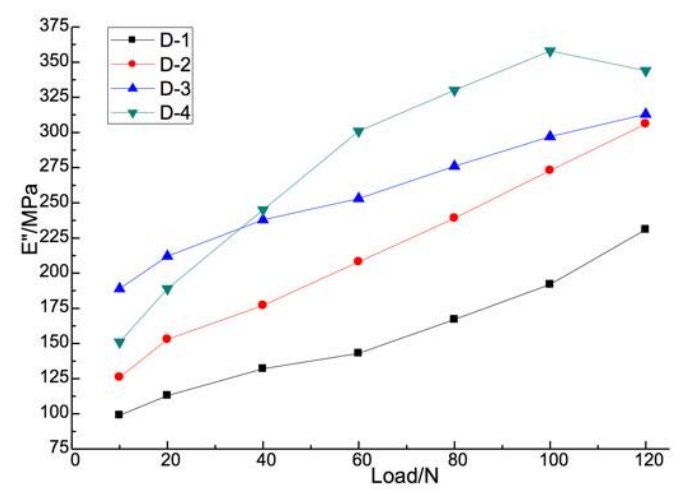

(b)

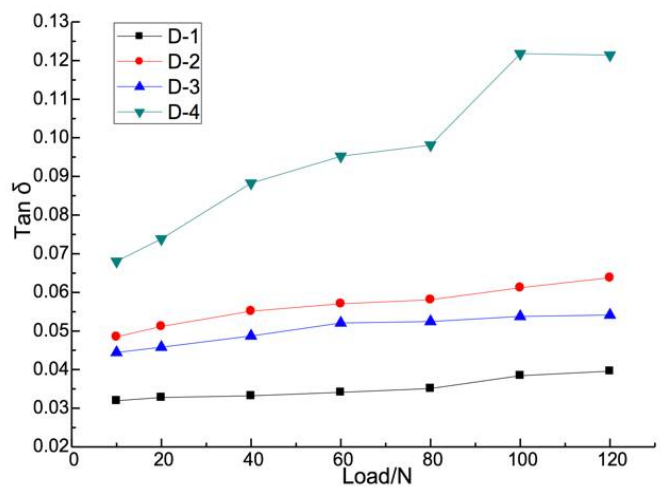

(c)

Figure 6. Dynamic elastic analysis of fiber reinforced CBPC composites showing the (a) storage modulus, (b) loss modulus, and (c) loss factor.

The microstructure motion units respond to the magnitude of the external load. As well the response is sensitive to the static and dynamic components of the load. A static load is equivalent to applying a tension force to the element in advance of the dynamic load, thus reducing the response to the dynamic load. That is, a larger static load reduces the available dynamic load and therefore reduces the dynamic strain. As well, a larger static load results in a larger storage modulus. The dynamic storage modulus of the samples with continuous carbon fiber exhibit significant load sensitivity and have a strong non-linearity.

Compared with the pure CBPC matrix, CBPC fiber composites have excellent ability of resistance to deformation. Both CBPC with PVA fiber and continuous fiber composites have good resistance to elastic deformation, while the CBPC with continuous fiber composites has the strongest resistance to viscous deformation. With the alternating load between $10 \mathrm{~N}$ and $120 \mathrm{~N}$, the specimens present viscoelastic mechanical properties that are related to elastic deformation. Increasing the magnesia content was efficient in improving the storage modulus and loss modulus of the viscoelastic materials.

\subsection{XRD Analysis of the CBPC Paste}

The results of XRD analysis of metakaolin, magnesia, and CBPC matrix are shown in Figure 7. In Figure 7a, the metakaolin has an amorphous microstructure, and the amorphous peak formed between $15^{\circ}$ and $35^{\circ}(2 \theta)$. There were small characteristic peaks of quartz found in the spectrum. As well, the diffraction peaks of kaolinite were also seen. In Figure 7b, it is seen that there were sharp diffraction peaks in the XRD pattern of magnesia. The sharp peaks show that the magnesia had 
high crystallinity. Figure 7c shows the XRD pattern of the hardened pure CBPC matrix. This shows an amorphous peak of CBPC pastes formed between $15^{\circ}$ and $35^{\circ}(2 \theta)$, which means that the CBPC paste had an amorphous microstructure. In the XRD pattern, the diffraction peaks of quartz and periclase in CBPC are caused by the raw materials of metakaolin and magnesia that were used. However, a different mineral, newberyite $\left(\mathrm{MgHPO}_{4} \cdot 3 \mathrm{H}_{2} \mathrm{O}\right)$, was also found in the hardened CBPC. This mineral was the reaction product of magnesia and phosphate solution. The newberyite mineral has fine needle-flake crystals $[1,23,24]$ which may benefit the strength development of the CBPC matrix. According to the study of Wagh et al. [25], the reaction mechanism of CBPC may include a 3D polymeric network structure (-Si-O-Al-O-P-) formed by the reaction of phosphate and metakaolin. Magnesia cannot fully react with phosphate in the current mixtures, so the periclase and its XRD diffraction peaks remain in the hardened CBPC matrix. The diffraction peak of newberyite was in proportion to the content of magnesia in the sample. From the analysis, although magnesia was not involved in polymerization, it could react with the phosphate solution to form the newberyite crystal. The reaction equation of magnesia and phosphate solution can be written as follows:

$$
2 \mathrm{MgO}+\mathrm{Al}\left(\mathrm{H}_{2} \mathrm{PO}_{4}\right)_{3}+\mathrm{H}_{2} \mathrm{O} \rightarrow \mathrm{MgHPO}_{4} \cdot 3 \mathrm{H}_{2} \mathrm{O}+\mathrm{AlPO}_{4} \cdot \mathrm{nH}_{2} \mathrm{O}
$$

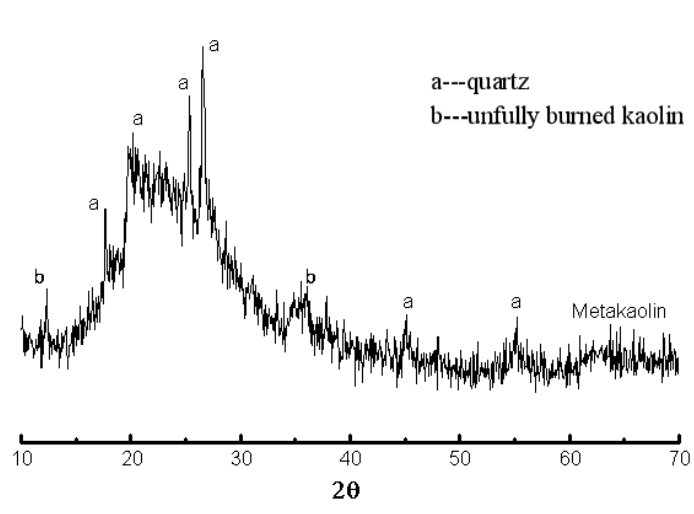

(a)

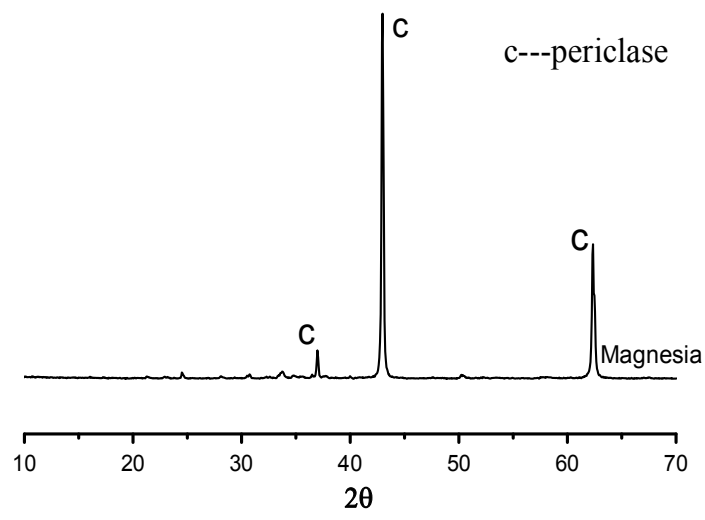

(b)

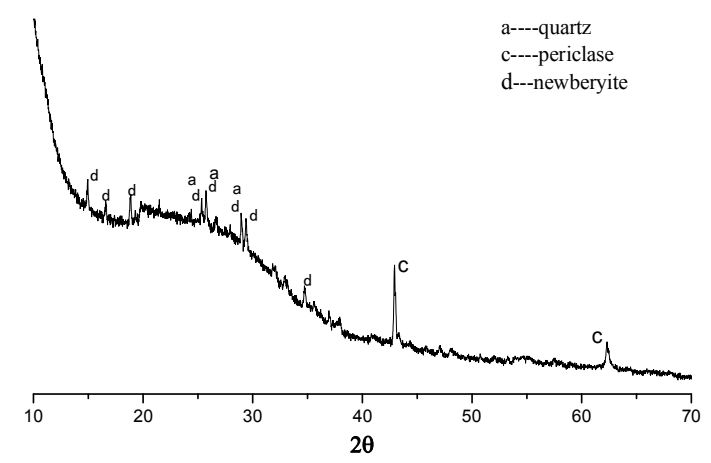

(c)

Figure 7. X-ray diffraction (XRD) spectra of (a) metakaolin, (b) magnesia, and (c) CBPC matrix.

\subsection{Microstructure of Fiber Reinforced CBPC Composites}

To investigate the microstructure of CBPC composites, XCT, and SEM analysis were performed for the PVA and carbon fiber reinforced CBPC composites samples after curing for 7 days. Figure 8 shows the SEM pictures of carbon fiber CBPC composites of samples F-9 and F-10. Figure 8a illustrates that the hardened CBPC matrix has a dense microstructure. The reaction products are closely bonded together, and there are no visible original cracks in the matrix indicating that CBPC has a continuous 
microstructure. There are no visible crystals in the SEM picture, demonstrating that the produced crystal in the CBPC matrix is likely fine and uniformly distributed in the matrix.

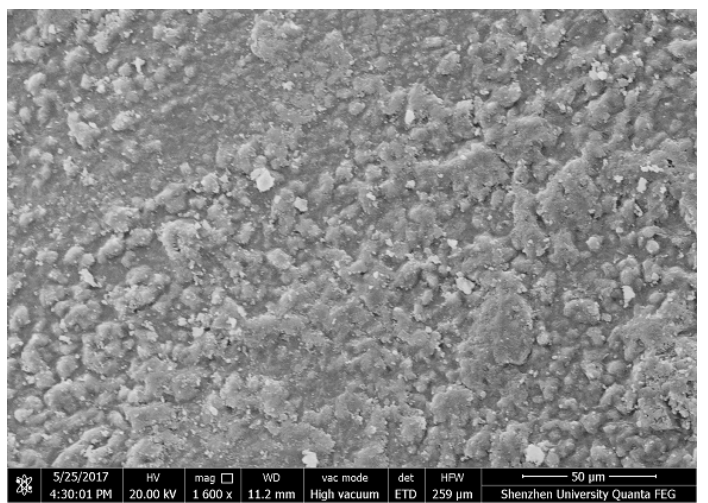

(a)

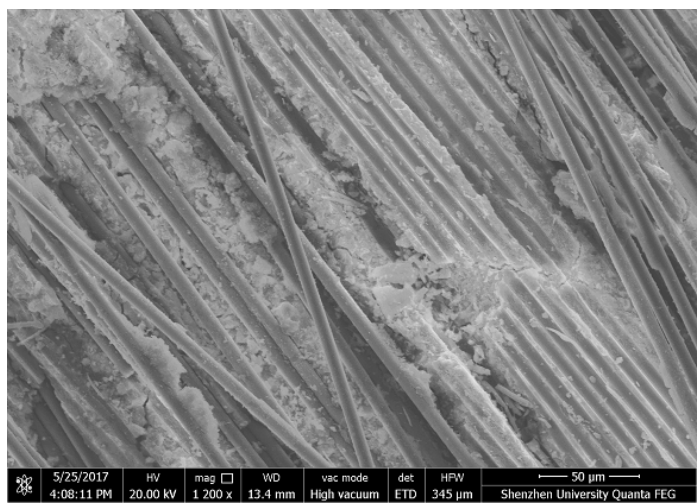

(b)

Figure 8. Electron scanning micrography (SEM) micrographs of fiber reinforced CBPC composites for (a) sample F-9 and (b) sample F-10.

Figure 9 shows the XCT analysis of PVA fiber CBPC composites sample F-10. Figure 9a displays one of the 2D plane figures scanned the sections by the XCT. The 2D figures were then used to complete the 3D reconstruction by Avizo software (Avizo 8.0, FEI, Hillsboro, OR, USA). The region size of the $3 \mathrm{D}$ reconstruction was $2.186 \mathrm{~mm} \times 2.621 \mathrm{~mm} \times 2.617 \mathrm{~mm}$, and the $3 \mathrm{D}$ reconstructed image is shown in Figure 9b.

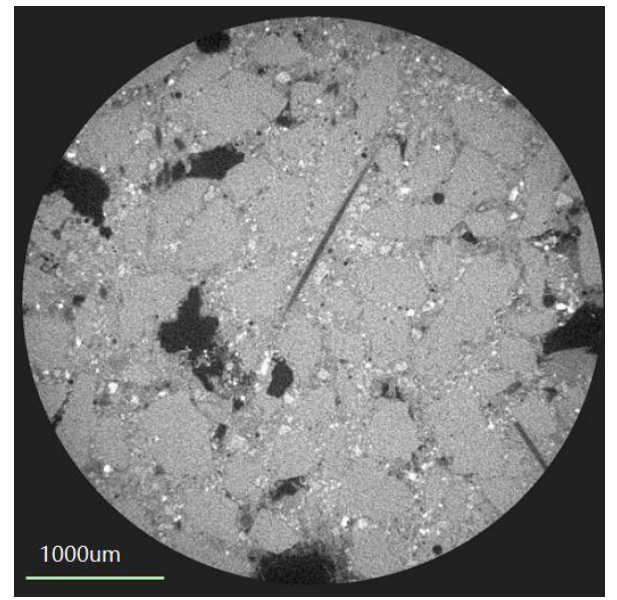

(a)

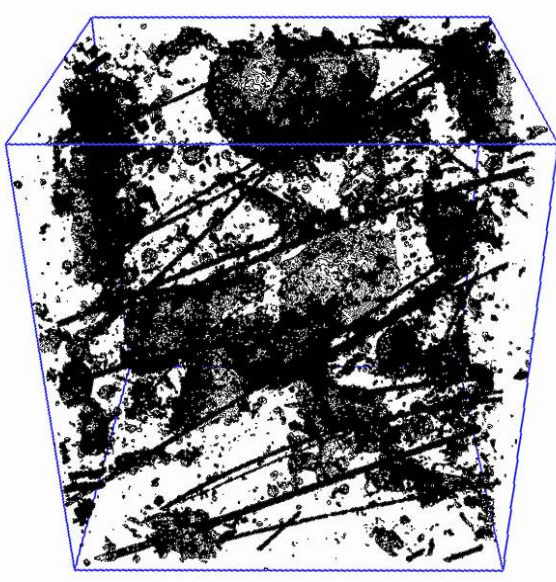

(b)

Figure 9. XCT analysis of fiber reinforced CBPC composites sample P-10 (a) XCT 2D plane figure;

(b) XCT 3D reconstructed image.

After the addition of PVA fibers and continuous carbon fibers, the flexural strength of CBPC was greatly improved. The increase of flexural strength can be partly revealed by the SEM and XCT analysis. In Figure 9b, the distribution of the continuous carbon fibers in the CBPC matrix is homogeneous. CBPC paste was bonded very well with the carbon fibers by permeating the spacing and getting through the continuous carbon fibers. Therefore, the matrix was able to transfer the load to the continuous carbon fibers without any interface problems, improving the mechanical property of the composites.

From Figure 9a, there are different gray values seen in the 2D XCT pictures. In this study, the gray value range is $0-255$ in the $2 \mathrm{D}$ plane pictures from the $\mathrm{XCT}$ scanning. Different gray values 
represent different materials in the CBPC matrix. The gray values decrease from white to dark black corresponding to the magnesia particles, phosphate gel, PVA fiber, and air voids that were introduced during CBPC mixing. In Figure 9b, the 3D XCT reconstruction image shows the uniformly distributed PVA fibers with no mutual winding seen. The uniformed distribution occurs because phosphates are a good dispersing agent for the fibers. The good distribution of fibers provides an important "bridge effect" during loading which helps prevent crack propagation. As a result, the toughness of composites with continuous fibers was significantly enhanced.

\section{Conclusions}

In this study, fiber reinforced CBPC composites were fabricated at indoor temperatures. The mechanical property and microstructure of the CBPC composites were studied. From the experimental results, the following conclusions are made.

1. Both PVA fiber and continuous carbon fiber can significantly improve the toughness of CBPC. When $0.8 \mathrm{wt} . \%$ PVA fibers were used, the flexural strength was about twice that of the control sample, and the modulus of elasticity was 3.01 GPa. For $1.5 \mathrm{wt} . \%$ PVA fibers, the flexural strength increased to $13.86 \mathrm{MPa}$, and the modulus of elasticity was $4.2 \mathrm{GPa}$. For the composite with one layer of carbon fiber sheet, the flexural strength was $14.8 \mathrm{MPa}$, which is about three times that of the control sample. When two layers of fiber sheets were used, the modulus of elasticity was $5.77 \mathrm{GPa}$, which was far higher than the control sample and the composites sample with PVA fiber. For three layers of carbon fiber sheets, the flexural strength reached $31.32 \mathrm{MPa}$, and the modulus of elasticity was $10.88 \mathrm{GPa}$.

2. The results of dynamic mechanical tests indicate that CBPC fiber composites belong to the inorganic polymer viscoelastic materials as it had elastic deformation under alternating load. CBPC composites with short fiber had better resistance to elastic deformation than CBPC composites with continuous carbon fiber.

3. Magnesia can improve the mechanical property of the CBPC fiber composites. When the Si/P mole ratio of CBPC paste was 2 and magnesia content was 15\%, the CBPC fiber composites had excellent flexural strength.

4. XRD analysis shows that CBPC matrix has an amorphous microstructure with residual quartz and magnesia in the matrix. A different mineral, newberyite, was observed to have been formed by the reaction of magnesia and phosphate. The SEM and XCT analyses show that the hardened CBPC matrix is dense, and the fiber can provide the "bridge effect" inside the fiber composite.

Author Contributions: Z.D. designed the experiments. Y.-Y.L. and C.L. performed the experiments, analyzed the data, and wrote the paper. Z.D. and J.L. reviewed the manuscript.

Funding: Please add: This research was funded by the National Natural Science Foundation of China (51472163 and 51172146).

Acknowledgments: Prof. George Zuo of University of Adelaide is greatly appreciated for proofreading the manuscript.

Conflicts of Interest: The authors declared that they have no conflicts of interest to this work.

\section{References}

1. Wagh, A.S. Chemically Bonded Phosphate Ceramics-Twenty-First Century Materials with Diverse Applications, 2nd ed.; Elsevier Science: Amsterdam, The Netherlands, 2016; pp. 141-155, ISBN 9780081003800.

2. Jeong, S.Y; Wagh, A.S. Chemically Bonded Phosphate Ceramics: Cementing the Gap Between Ceramics and Cements. Mater. Technol. 2002, 18, 1-24.

3. Colorado, H.A.; Hiel, C.; Hahn, H.T.; Yang, J.M. Wollastonite-based chemically bonded phosphate ceramic composites. In Metal, Ceramic and Polymeric Composites for Various Uses; Cuppoletti, J., Ed.; In Tech: London, England, 2011. 
4. Wagh, A.S.; Jeong, S.Y. Formation of Chemically Bonded Ceramics with Magnesium Dihydrogen Phosphate Binder. U.S. Patent 6,776,837, 17 August 2004.

5. Ding, Z.; Dong, B.; Xing, F.; Han, N.; Li, Z. Cementing Mechanism of Potassium Phosphate Based Magnesium Phosphate Cement. Ceram. Int. 2012, 38, 6281-6288. [CrossRef]

6. Rouzic, M.L.; Chaussadent, T.; Platret, G.; Stefan, L. Mechanisms of k-struvite formation in magnesium phosphate cements. Cem. Concr. Res. 2007, 91, 117-122. [CrossRef]

7. Abdelrazig, B.E.I.; Sharp, J.H. Phase changes on heating ammonium magnesium phosphate hydrates. Thermochim. Acta 1988, 129, 197-215. [CrossRef]

8. Abdelrazig, B.E.I.; Sharp, J.H.; El-Jazairi, B. The microstructure and mechanical properties of mortars made from magnesia-phosphate cement. Cem. Concr. Res. 1989, 19, 247-328. [CrossRef]

9. Ding, Z.; Li, Z. Effect of aggregates and water contents on the properties of magnesium phospho-silicate cement. Cem. Concr. Compos. 2005, 27, 11-18. [CrossRef]

10. Hall, D.A.; Stevens, R.; Jazairi, B.E. Effect of Water Content on the Structure and Mechanical Properties of Magnesia-Phosphate Cement Mortar. J. Am. Ceram. Soc. 2005, 81, 1550-1556. [CrossRef]

11. Soudée, E.; Péra, J. Mechanism of setting reaction in magnesia-phosphate cements. Cem. Concr. Res. 2000, 30, 315-321. [CrossRef]

12. Li, Y.; Sun, J.; Chen, B. Experimental study of magnesia and M/P ratio influencing properties of magnesium phosphate cement. Constr. Build. Mater. 2014, 65, 177-183. [CrossRef]

13. Frantzis, P.; Baggott, R. Bond between reinforcing steel fibers and magnesium phosphate/calcium aluminate binders. Cem. Concr. Res. 2000, 22, 187-192. [CrossRef]

14. Pera, J.; Ambroise, J. Fiber-reinforced Magnesia-phosphate Cement Composites for Rapid Repair. Cem. Concr. Compos. 1998, 20, 31-39. [CrossRef]

15. Colorado, H.A.; Hiel, C.; Hahn, H.T. Chemically bonded phosphate ceramics composites reinforced with graphite nanoplatelets. Compos. Part A Appl. Sci. Manuf. 2011, 42, 376-384. [CrossRef]

16. Colorado, H.A.; Hahn, H.T.; Hiel, C. Pultruded glass fiber-and pultruded carbon fiber-reinforced chemically bonded phosphate ceramics. J. Compos. Mater. 2011, 45, 2391-2399. [CrossRef]

17. Pitak, Y.N.; Churilova, Y.V. The Effect of Aluminum Phosphate Binder on the Crystallization of Mullite-Silica Fibers. Refract. Ind. Ceram. 2004, 45, 275-276. [CrossRef]

18. Chiou, J.M.; Chung, D.D.L. Improvement of the temperature resistance of aluminium-matrix composites using an acid phosphate binder. J. Mater. Sci. 1993, 28, 1447-1470. [CrossRef]

19. Zhang, D. Development and application of high temperature radome materials. Aerosp. Mater. Technol. 2001, $6,1-3$.

20. Ge, X.; Wang, R.; Liu, H.X. Research progress of the folded wing of missile composites. In Proceedings of the Seventeenth Annual Conference of FRP/Composites, Guangzhou, China, 2008.

21. Li, J.G.; Cao, M.S.; Zhang, Y. Study abroad through the electrical properties of high-temperature materials Wave progress. Mater. Eng. 2005, 2, 59-62.

22. Yu, H.; Zhou, C.W. Micromechanical analysis of viscoelastic dynamic properties of fiber composites. J. Vib. Eng. 2011, 24, 359-362.

23. Wagh, A.S.; Jeong, S.Y. Chemically bonded phosphate ceramics: III, reduction mechanism and its application to iron phosphate ceramics. J. Am. Ceram. Soc. 2003, 86, 1850-1855. [CrossRef]

24. Wagh, A.S.; Grover, S.; Jeong, S.Y. Chemically Bonded Phosphate Ceramics: II, Warm-Temperature Process for Alumina Ceramics. J. Am. Ceram. Soc. 2003, 86, 1845-1849. [CrossRef]

25. Wagh, A.S.; Jeong, S.Y. Chemically bonded phosphate ceramics: I, a dissolution model of formation. J. Am. Ceram. Soc. 2003, 86, 1838-1844. [CrossRef]

(C) 2018 by the authors. Licensee MDPI, Basel, Switzerland. This article is an open access article distributed under the terms and conditions of the Creative Commons Attribution (CC BY) license (http:/ / creativecommons.org/licenses/by/4.0/). 